\title{
Dominance relationships in a family pack of captive arctic wolves (Canis lupus arctos): the influence of competition for food, age and sex
}

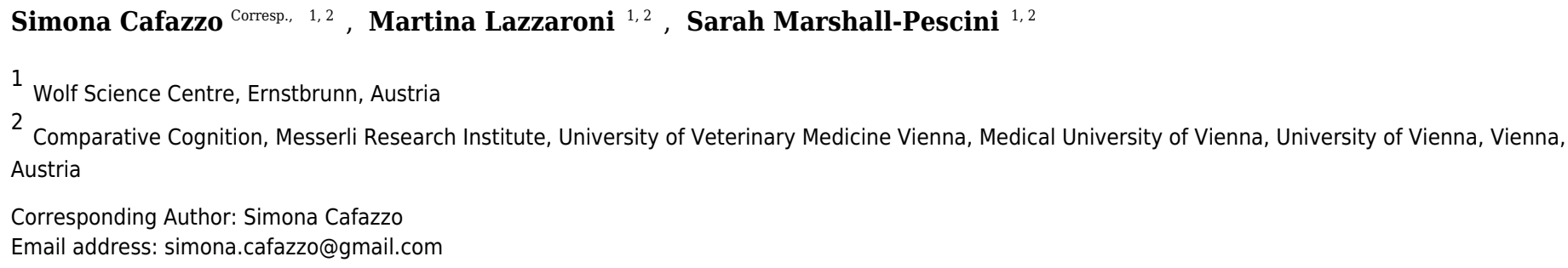

Background. Dominance is one of the most pervasive concepts in the study of wolf social behaviour but recently its validity has been questioned. For some authors the bonds between members of wolf families are better described as parent-off-spring relationships and the concept of dominance should be used just to evaluate the social dynamics of nonfamilial captive pack members (e.g. Mech \& Cluff, 2010). However, there is a dearth of studies investigating dominance relationships and its correlates in wolf family packs. Methods. Here, we applied a combination of the most commonly used quantitative methods to evaluate the dominance relationships in a captive family pack of 19 Arctic wolves. Results. We found a significant linear and completely transitive hierarchy based on the direction of submissive behaviours and found that dominance relationships were not influenced by the competitive contexts (feeding vs. non-feeding context). A significant linear hierarchy also emerges amongst siblings once the breeding pair (the two topranking individuals) is removed from analyses. Furthermore, results suggest that wolves may use greeting behaviour as a formal signal of subordination. Whereas older wolves were mostly dominant over younger ones, no clear effect of sex was found. However, frequency of agonistic (submissive, dominant and aggressive) behaviours was higher between female-female and male-male dyads than female-male dyads and sex-separated linear hierarchies showed a stronger linearity than the mixed one. Furthermore, dominance status was conveyed through different behavioural categories during intrasexual and inter-sexual interactions. Discussion. Current results highlight the importance of applying a systematic methodology considering the individuals' age and sex when evaluating the hierarchical structure of a social group. Moreover, they confirm the validity of the concept of dominance relationships in describing the social bonds within a family pack of captive wolves. 
1 Dominance relationships in a family pack of captive arctic wolves (Canis lupus arctos): the

2 influence of competition for food, age and sex

3

4 1,2Simona Cafazzo, ${ }^{1,2}$ Martina Lazzaroni, 1,2Sarah Marshall-Pescini

$5 \quad{ }^{1}$ Wolf Science Centre, Ernstbrunn, Austria

$6{ }^{2}$ Comparative Cognition, Messerli Research Institute, University of Veterinary Medicine

7 Vienna, Medical University of Vienna, University of Vienna, Vienna, Austria

8

9 Corrisponding Author:

10 Simona Cafazzo ${ }^{1,2}$

11 Nikolaus Heid-Straße 74/1, Stockerau, 2000, Austria

12 Email address: simona.cafazzo@gmail.com 


\section{Abstract}

Background. Dominance is one of the most pervasive concepts in the study of wolf social behaviour but recently its validity has been questioned. For some authors the bonds between members of wolf families are better described as parent-off-spring relationships and the concept of dominance should be used just to evaluate the social dynamics of non-familial captive pack members (e.g. Mech \& Cluff, 2010). However, there is a dearth of studies investigating dominance relationships and its correlates in wolf family packs.

Methods. Here, we applied a combination of the most commonly used quantitative methods to evaluate the dominance relationships in a captive family pack of 19 Arctic wolves.

Results. We found a significant linear and completely transitive hierarchy based on the direction of submissive behaviours and found that dominance relationships were not influenced by the competitive contexts (feeding vs. non-feeding context). A significant linear hierarchy also emerges amongst siblings once the breeding pair (the two top-ranking individuals) is removed from analyses. Furthermore, results suggest that wolves may use greeting behaviour as a formal signal of subordination. Whereas older wolves were mostly dominant over younger ones, no clear effect of sex was found. However, frequency of agonistic (submissive, dominant and aggressive) behaviours was higher between female-female and male-male dyads than femalemale dyads and sex-separated linear hierarchies showed a stronger linearity than the mixed one. Furthermore, dominance status was conveyed through different behavioural categories during intra-sexual and inter-sexual interactions.

Discussion. Current results highlight the importance of applying a systematic methodology considering the individuals' age and sex when evaluating the hierarchical structure of a social 
group. Moreover, they confirm the validity of the concept of dominance relationships in describing the social bonds within a family pack of captive wolves.

\section{Introduction}

In group-living animals the natural asymmetries among individuals in their ability to prevail in competition may result in social dominance hierarchies. In general dominantsubordinate relationships may be defined as long-term dyadic relationships characterised by an asymmetric distribution of agonistic behaviours (Drew, 1993). In line with this definition, dominance relationships are measured in terms of the degree of the unidirectionality of behaviours exhibited within a dyad (directional consistency index, Van Hoof \& Wensing, 1987), a high unidirectionality, for example, would emerge if A frequently showed submissive behaviours to $\mathrm{B}$, but $\mathrm{B}$ was never observed showing a submissive behaviour to $\mathrm{A}$. When dominant-subordinate relationships characterize all or most dyads in a social group, then it may be possible to describe the overall social structure of that group as a 'linear dominance hierarchy'. To fit the linear hierarchy model, all or most relationships between group members have to be transitive $(\mathrm{A}>\mathrm{B}>\mathrm{C}>\mathrm{D})$, rather than $\operatorname{circular}(\mathrm{A}>\mathrm{B}$ and $\mathrm{B}>\mathrm{C}$ but $\mathrm{C}>\mathrm{A})$, (Landau, 1951; Appleby, 1983; Van Hoof \& Wensing, 1987; de Vries, 1995; Shizuka \& McDonald, 2012; Shizuka \& McDonald, 2014). However, a major limitation of the linearity index is that it becomes negatively biased when some pairs of individuals fail to interact (null dyads; de Vries, 1995; Klass \& Cords, 2011). Therefore, a low level of linearity may not necessarily indicate the absence of transitivity but may be due to the high percentage of null dyads. More recently, triangle transitivity $\left(\mathrm{t}_{\mathrm{tri}}\right)$, which determines the level of hierarchy transitivity and is less sensitive to unknown relationship (Shizuka \& McDonald, 2012; Shizuka 
$59 \&$ McDonald, 2014), has been used as a successful alternative (e.g. Norscia \& Palagi, 2015).

60 Triangle transitivity is based on the transitivity of dominance relations among sets of three

61 individuals that all interact with each other (Shizuka \& McDonald, 2012). The method by

62 Shizuka \& McDonald (2012) follows logic similar to that of de Vries (1995), but the procedure

63 is conducted without filling in zero dyads (i.e. unknown relationships) with randomized

64 dominance relations. In fact, filling in zero dyads artificially decreases the level of linearity

65 because it creates cyclic (and not transitive) triads, e.g., A dominates B, B dominates C, and C

66 dominates $\mathrm{A}(\mathrm{A}>\mathrm{B}>\mathrm{C}>\mathrm{A})$. Triangle transitivity and linearity are equivalent when the

67 dominance relations of all dyads are known but since such complete observations are rare in

68 empirical studies (Shizuka \& McDonald, 2012); using both measures may provide a better

69 assessment of the hierarchical organization of a group.

As clearly demonstrated by Shizuka \& McDonald (2015), another factor affecting the

71 linearity is the interaction rates of the top-ranked individuals. In fact, in groups where alpha

72 individuals engaged in more contests, there were more double-dominant triads (where A

dominates both $\mathrm{B}$ and $\mathrm{C}$ and any relationships is detectable between $\mathrm{B}$ and $\mathrm{C}$ ) and fewer pass-

74 along triads (where A dominates B, B dominates $\mathrm{C}$ but any relationships is detectable between $\mathrm{A}$ and C), suggesting that top-ranking individuals may have a disproportionate influence on dominance hierarchies and highlighting the necessity to control for that (Shi et al., 2009, Modlmeier et al., 2014; Shizuka \& McDonald, 2015).

When a significant degree of linearity/transitivity exists in a group, the rank order most consistent with a linear hierarchy may be obtained via the binary dyadic dominance relationship method (I\&SI, de Vries, 1998), which allows the characterization of the relationship between two individuals in a group. However, the dyadic relationship between individuals may very across 
82 contexts since the capacity and motivation of animals to obtain access to specific resources (e.g.

83 feeding, mating privileges etc.) may vary considerably. Since the costs and benefits of winning a

84 given conflict may be context-dependent, a dyad member may be dominant in one context but

85 not in others (Hand, 1986) thereby influencing the overall agonistic rank position of members in

86 a pack. Such differences in rank relationships depending on context have indeed been reported

87 for several species ranging from chimpanzees to cats (Noë, de Waal, \& Van Hooff, 1980;

88 Bonanni et al. 2007).

89 A hierarchy within a group can be described in terms of the asymmetry amongst

90 individuals in winning conflicts (agonistic dominance), however it can also be described in terms

91 of formal dominance (de Waal, 1989). The latter is characterized by the exchange of ritualized

92 signals and/or greeting rituals, the direction of which is independent of the social context. When

93 the agonistic dominance is accepted by the subordinates, dominance relationships are stable (i.e.

94 no reversals or intransitivity in the hierarchy emerge; e.g. Fournier \& Festa-Bianchet, 1995), and

95 formal and agonistic dominance coincide. In this case, the exchange of hierarchical status

96 information may be conveyed mainly through formalized submissive signals, resulting in a low

97 frequency of overt aggressive conflicts (de Waal, 1989).

98 Wolves are a particularly interesting case in which to investigate hierarchical relationships

99 since the applicability of this concept to this species has been suggested to depend largely on the 100 type of social structure of the pack (e.g. Block, 2002; Mech \& Cluff, 2010). The typical wild wolf

101 social structure is based around a bonded male-female pair that raises pups communally. The

102 offspring of a bonded pair may forego dispersal and remain with their native pack and help raise

103 later litters (e.g. Mech, 1999, 2000; Packard, 2003). Traditionally, dominance relationships in 
104 wild wolf packs have been described in terms of the "age-(sex)-graded model" (Zimen, 1982;

105 Packard, 2003, pp 54) in that within these family groups, there is a natural dominance order in

106 which offspring submit to parents, and puppies submit to both parents and older siblings (Mech,

107 1999). This model has been presented in one of two ways: either simply as separate linear

108 hierarchies for each sex influenced but not determined by age (Schenkel, 1967; Zimen, 1982) or

109 as male dominance over females within each age class (Rabb, Woolpy \& Ginsburg, 1967; Fox,

110 1980; Zimen, 1982; Van Hooff \& Wensing, 1987; Savage, 1988).

111 In contrast to this traditional "age-(and sex)-graded" model, more recently several authors

112 claim that the relationships in the typical wolf family, are better described as parents-offspring-

113 pups relationships rather than as a pecking order dominated by an alpha male (alpha, beta down

114 to omega animals; e.g. Bloch, 2002; Fatjó et al., 2007; Mech \& Cluff, 2010). Thus, a dominance

115 hierarchy within the typical 'nuclear' family pack could be alternatively viewed as just a

116 reflection of the age, sex and reproductive structure of the group (Mech, 1999). Although the

117 same authors suggest that traditional concepts of dominance hierarchy may still be useful for

118 evaluating the social dynamics of captive families composed of artificially assembled unrelated

119 individuals (Mech, 1999; Packard, 2003; Fatjó et al., 2007).

120 To date, although dominance relationships have been described in several packs of wild

121 wolves (e.g. Mech, 1999; Bloch, 2002; Peterson et al. 2002; Sands \& Creel, 2004; Baan et al.

122 2014), a quantitative assessment and statistical validation of the existence of linear dominance

123 relationships has been carried out only in wolves living in captivity and mostly in packs

124 consisting of either 'complex families' i.e. composed of artificially assembled unrelated

1 The model was originally called the "age-graded model" but since it entails also an effect on sex on dominance relationships for a major clarity we prefer refers to it as the "age-(sex)-graded model" 
125 individuals (e.g. Packard, 2003 for a review; Mazzini et al 2013) or 'disrupted families' i.e. in

126 which one or both of the original parents are missing (e.g. Packard, 2003 for a review; Cordoni

127 \& Palagi, 2008). To our knowledge, only two studies systematically tested and confirmed the

128 existence of a linear hierarchy between pack members in typical wolf families ('nuclear families'

129 with parents and multiple generations of offspring and 'extended families' consisting of parents

130 plus one of more of their siblings, and their direct offspring) (Van Hoof \& Wensing, 1987;

131 Romero, et al., 2014).

132 Formal signals of dominance or submission have been described in wild wolves and 133 captive wolves (Schenkel, 1947; Feddersen-Petersen, 2004), for example Van Hoof \& Wensing,

134 (1987) found that postural displays (namely high posture and low posture) were exhibited

135 consistently from one partner to the other and were therefore suggested as indicators of formal

136 dominance. However, signals of formal dominance have so far been systematically tested only in

137 domestic dogs (Cafazzo et al., 2010; van der Borg et al., 2015). In particular, mouth licking

138 associated with tail wagging (so called 'greeting' behaviour) occurring often during greeting

139 ceremonies fulfilled the criteria of a formal signal of subordination in both free-ranging (Cafazzo

140 et al., 2010) and group housed dogs (van der Borg et al., 2015).

In previous studies, although a linear hierarchy clearly emerged within the pack, there

142 was no quantitative assessment of the validity of the "age-(sex)-graded' model. Indeed, although

143 female and male separate linear hierarchies have been commonly described qualitatively in

144 captive wolves (e.g. Schenkel, 1947; Zimen, 1982), results tend to go in the opposite direction to 145 descriptions of social relationships between the sexes in wild wolves (e.g. Clark, 1971; Haber,

146 1977; Mech, 1999). However, no study has been carried out to assess the validity of this model

147 neither in the wild nor in captivity. Furthermore, despite having been observed in a number of 
148 species, no study, to our knowledge has evaluated the potential effect of different competitive 149 contexts on dominance relationships in wolves.

150 Hence, in the current study we applied a combination of the most commonly used

151 quantitative methods to evaluate dominance relationships, in order to investigate 1) whether an

152 agonistic dominance hierarchy could describe the relationships between members of a captive

153 family pack of Arctic wolves and whether a hierarchical structure would remain consistent

154 (amongst siblings) when the top-ranking individuals (i.e. the breeding pair) were removed from

155 analyses (see Shizuku \& McDonald 2015); 2) whether the hierarchy remained consistent in a

156 feeding and non-feeding context; 3) which behaviours may be the best indicators of dominance,

157 4) whether mouth licking associated to tail wagging (greeting, hereafter) can be considered a

158 formal signal of submission in wolves, as has been found in dogs. Finally, to help address the

159 controversy regarding the validity of the dominance concept in wolves, we also aimed to assess

160 5) if the typical age-(and sex)-graded model could adequately describe the relationships of the

161 nuclear family pack of wolves observed.

162 Materials \& Methods

163 Ethics statement

164 The study was purely observational with no manipulation of animals. The relevant 165 committee, Tierversuchs-kommission am Bundesministerium für Wissenschaft und Forschung 166 (Austria) allows us running this research without special permissions regarding animals (wolves) 167 since this is not required in such socio-cognitive studies in Austria (Tierversuchsgesetz 2012168 TVG 2012).

\section{Subjects and study site}


171 (Moravia, Czech Republic) during a period of 5 months (Jan 2014-May 2014). The pack was

172 composed of 20 individuals: 7 adult males, 8 adult females, 3 sub-adult males, and 8 sub-adult

173 females. Adults were defined as individuals older than two years and sub-adults as individuals

174 younger than 2 years. The pack was structured as a nuclear family with all members born into the

175 pack except for the breeding male and the two unrelated breeding females. The number of

176 individuals decreased to 14 by the end of the period of study (Table 1) because 6 wolves were

177 removed from the pack. Specifically, one adult breeding female was removed because she was

178 badly injured by the other breeding female during the reproductive season. Two adult and two

179 sub-adult wolves were sold to another zoo. Finally an adult male was removed because of

180 continuous mobbing episodes from the whole pack.

181 The pack was kept from February to March in an enclosure of approximately $7000 \mathrm{~m}^{2}$

182 located in a naturally hilly area equipped with trees, branches and dens. For the rest of the study

183 period the animals were restricted in a smaller enclosure of about $3000 \mathrm{~m}^{2}$. The animals were fed

184 with pieces of meat, which were put on a table of $2 \mathrm{~m}^{2}, 4$ or 5 times every week in the early

185 afternoon. Water was available ad libitum. No stereotypic or aberrant behaviours characterized

186 the study group.

\section{Data collection}

188 The pack was observed 6 days per week for 2-3 hours a day, either in the morning or the 189 afternoon (the afternoon period included feeding time). Before commencing systematic data 190 collection, the observer (M.L.) underwent a 7-month training period on wolf behaviour whilst 191 collecting data at the Wolf Science Centre (Ernstrbunn, Austria). Then she carried out some 
192 preliminary observations (50 h) in order to 1$)$ identify all individuals belonging to the pack and 193 2) establish the data collection methods.

Wolf behaviour was observed in 2 different social contexts: in the presence of food and in

195

196

197

198

200

201

202

203

204

205

206

207

208

209

210

211

212

213 the absence of this source of competition. Data collection was carried out following Altmann's (1974) methods: the focal animal sampling method was used in the absence of sources of competition, whereas the subgroup animal sampling method was used in the presence of food. During focal-subgroup sessions all occurrences of agonistic and greeting interactions were recorded (Table 2). The "ad libitum" sampling method (Altmann, 1974) was also used to record all agonistic behavioural patterns as well as greetings occurring out of focal-subgroup sampling sessions; we gathered $154 \mathrm{~h}$ of observations, distributed over 63 days.

Each individual measure of all behaviour patterns was corrected for animal observation time because the latter varied between individuals; since some animals were removed from the pack earlier.

\section{Agonistic dominance hierarchy and behavioural analyses}

In order to determine the agonistic dominance hierarchy, the outcomes of aggressive, submissive, and dominance dyadic interactions (see Table 2 for a description) were ranked in 3 different squared matrices with winners on one axis and losers on the other. This procedure was applied to interactions in both social contexts (i.e. presence and absence of food), resulting in a total of 6 matrices, 3 for each context. In the same way, in order to analyse the use of greeting as a formal signal of subordination, all greeting interactions observed (Table 2) were ranked in a squared matrix. For each matrix, linearity and transitivity (and their statistical significance), as well as directional consistency, were calculated. 

ranged from 0 to 1 . Values of 0 indicate a complete absence of linearity and transitivity (i.e. no hierarchy) and a complete bidirectionality; values of 1 indicate a perfect linear hierarchy, the absence of circular triads and a complete unidirectionality. method which minimizes inconsistencies and strengths of inconsistencies in dominance relationships (de Vries, 1998). An inconsistency occurs when individual j dominates i, and j's rank is lower than i's (de Vries, 1998). The rank difference between two individuals involved in an inconsistency is the strength of that inconsistency (de Vries, 1998). evenly between the highest $(+1)$ and the lowest $(-1)$, with the median rank being scored as 0 (East \& Hofer, 2001). Then, in order to test the effect of social context, age and gender, we calculated the Spearman's correlation coefficient between 1) I\&SI rank orders in the two competitive contexts, 2) between inter-sexual and intra-sexual hierarchies, and 3) between rank orders and age.

229 To classify greeting as a formal indicator of subordination we assessed whether it fit specific criteria: a) completely unidirectional (DCI =1), b) shown between most of the pack members (no null dyads) and c) correlation with dominance relationships based on agonistic Vries, H. \& Van Elsacker, 2000). clustered . 
237 randomizations; Noldus Information Technology, Wageningen, The Netherlands; de Vries, Netto

239 (StatSoft Italy s.r.1. 2005). We calculated the proportion of transitive triangles relative to all triangles $(\mathrm{Pt})$, the triangle transitivity metric $\left(\mathrm{t}_{\text {tri }}\right)$ and its statistical significance using the codes provided in Shizuka \& McDonald (2012); supplementary material; errata corrige: Shizuka \& McDonald, 2014; package 'statnet', Handcock et al., 2003) in the R programme version 3.2.3 (R Development Core Team, 2011). The alpha male and female totalized just under half of our data points in all three categories of behaviours considered (41.84\% of dominance behaviours; $44.06 \%$ of aggressive behaviors; $51.46 \%$ of submissive behaviors received). Hence, taking into account the potential disproportionate role of these individuals in affecting the linearity of the

247 hierarchy (as suggested by Shizuku \& McDonald 2015) we re-ran the analyses described above 248 without these two animals.

249 In order to investigate whether the dyadic distribution of greeting was influenced by rank, age and sex we ran a generalized linear mixed model (GLMM with a Poisson distribution) with

251 the frequency of greeting behaviour as the response factor and sex combination of the dyad

252 (female-female, male-male and female-male), age difference expressed in months and rank

253 relationship between actor and receiver as independent factors. The identity of the actor and the 254 dyad were entered as random factors. Finally, to investigate the effect of sex on the distribution 255 of agonistic behaviours we ran a generalized linear mixed model (GLMM with a Poisson 256 distribution) with the frequency of agonistic behaviour as the response factor and gender 257 combination of the dyad (female-female, male-male and female-male) as the independent factor.

258 The identity of both individuals in the dyad was entered as random factors. 
The generalized linear mixed models were calculated using the codes provided in 1me4-

260

261

262

263

264

265

266

package (Bates et al., 2016), in R version 3.2.3 (R Development Core Team, 2011).

\section{Results}

\section{1) Agonistic dominance relationships in the absence and presence of food}

The directional consistency (DCI), linearity $\left(h^{\prime}\right)$, the number and strength of inconsistency (I\&SI), the proportion of transitive triangles relative to all triangles $(\mathrm{Pt})$, and the triangle transitivity metric $\left(t_{\text {tri }}\right)$ for each agonistic behavioural category in the two different contexts analysed (in the presence of food and in its absence) are summarised in Table 3.

\section{Agonistic dominance in the absence of food}

Aggressive interactions $(\mathrm{N}=388)$ did not show significant linearity; nevertheless, the behaviour showed a good level of unidirectionality. A significant linear dominance hierarchy, emerged based on the direction of both submissive behaviours $(\mathrm{N}=336$ interactions $)$ and dominance behaviour ( $\mathrm{N}=469$ interactions). However, the linearity for both behavioural categories was not high, although submissive and dominance behaviours were both highly unidirectional. Based on these results we applied the I\&SI method to both behavioural categories to find the best rank order to fit the linear model. Rank order based on submissive behaviour was positively correlated with the rank order based on dominance behaviour $(\mathrm{rs}=0.85, \mathrm{n}=19, \mathrm{p}=$ 0.0001) but the former resulted in an inconsistency of a lower strength than the latter. Finally, both dominance and submissive behaviours showed a high value of triangle transitivity, indicating that the low level of linearity was due to the high percentage of null dyads $(52.05 \%$ both) than to a real absence of transitivity. Agonistic behaviour in the presence of food 
Aggressive interactions $(\mathrm{N}=277)$ recorded in the presence of food showed a significant

282 level of linearity but a very low unidirectionality. Both dominance $(\mathrm{N}=272$ interactions $)$ and

\section{3}

submissive behaviour ( $\mathrm{N}=214$ interactions) also showed a significant but low level of linearity and the highest values of unidirectionality. The rank orders based on aggressive behaviour was correlated to those based on dominance and submissive behaviours ( $r s=0.72, n=19, p=$ $0.0005 ; \mathrm{rs}=0.68, \mathrm{n}=19, \mathrm{p}=0.001$, respectively) but it resulted in a high number of inconsistencies. The dominance rank order was correlated to the submissive rank order ( $\mathrm{rs}=$ $0.75, \mathrm{n}=19, \mathrm{p}=0.0002)$ and both generated 1 inconsistency with a strength of 2 for submissive behaviours and a strength of 4 for dominance behaviours. All the behavioural categories showed a high triangle transitivity, with dominance behaviours showing the highest value, indicating that, as in the absence of food, the low level of linearity was due to the high percentage of null dyads (aggressive behaviour: 51.86\%, submissive behaviour: $60.82 \%$, dominance behaviour: $63.13 \%$ ) rather than to a real absence of transitivity.

In sum, both dominance and submissive behaviours showed a significant linearity, higher values of directionality and triangle transitivity, and a lower number of inconsistencies than aggressive behaviours, resulting in the better measures of dominance relationships.

\section{2) Comparison of agonistic dominance in the absence, and in the presence of food}

The I\&SI rank orders based on submissive behaviours in the two contexts were highly correlated $(\mathrm{rs}=0.81, \mathrm{n}=19, \mathrm{p}=0.00008)$. In the same way, the I\&SI rank based on dominance behaviours found in the absence of food was highly correlated with the rank based on dominance behaviours found in the presence of food $(\mathrm{rs}=0.71, \mathrm{n}=19, \mathrm{p}=0.0007)$. We could reasonably assert that the slight differences in the rank orders were probably due to the quite high percentage 
303 of null dyads observed in each context. Therefore, dominance relationships between wolves do

304 not appear to be affected by the competitive contexts.

305

306

307

308

309

310

311

312

313

314

315

316

317

318

319

320

321

322

323

324

\section{3) Which behavioural category is the best indicator of dominance relationships?}

Considering that from the previous analyses a high correlation was found in the presence and absence of food and in order to minimize the number of null dyads and hence obtain the most reliable dominance hierarchy, the outcomes of all submissive dyadic interactions $(\mathrm{N}=550)$ and all dominance interactions $(\mathrm{N}=741)$ were ranked in two different squared matrices. For both submission and dominance interactions we found a high level of directionality, significant levels of linearity and high triangle transitivity (Table 3). By re-ordering the two matrices following the I\&SI method we found two highly correlated rank orders ( $r s=0.90, N=19, p=0.0001$; Figure 1). The alpha male and alpha female were the highest in rank, although they exchanged positions between the two hierarchies, with the alpha female being the highest in rank in hierarchy based on submissive behaviours and the alpha male being the highest in rank in the hierarchy based on dominance behaviours. Nevertheless, the matrix of dominance behaviour generated 2 inconsistencies with a total strength of 9. Conversely, the matrix of submissive behaviours (Table 4) showed no inconsistencies and revealed the highest triangle transitivity. Therefore, we conclude that submission can be considered the most reliable indicator of linear dominance relationships in our pack.

Excluding the alpha male and female from the analyses, we still found a highly significant linear hierarchy based on both submissive and dominance behaviours (Table 3). Although both linearity and unidirectionality were lower than those obtained including the breeding pair in the analyses, rank orders were precisely the same. The triangle transitivity of dominance behaviours 
325 decreased while that of submissive behaviour remained the same, showing again a complete

326 transitivity.

327 4) Can greeting behaviour be considered a signal of formal submission?

328 Greeting interactions $(\mathrm{N}=182)$ showed a significant but very low linearity index $\left(\right.$ ILT: $\mathrm{h}^{\prime}=$ $3290.34, \mathrm{p}=0.008)$. Alpha male and the alpha females displayed greetings towards each other. This 330 determined an incomplete, yet still very high, level of unidirectionality $(\mathrm{DCI}=0.98)$. The 331 complete triangle transitivity $\left(\mathrm{t}_{\mathrm{tri}}=1.000, \mathrm{p}=0.000\right)$ indicated that the low level of linearity was 332 likely due to high percentage of null dyads (66.08\%) and not due to the absence of transitivity.

333 Although the linearity was statistically significant, due to the high percentage of null dyads, the 334 I\&SI rank order based on greeting was considered to be unreliable. The individual frequency of 335 greetings displayed was not correlated to the I\&SI agonistic rank $(\mathrm{rs}=-0.13, \mathrm{n}=19, \mathrm{p}=0.58)$

336 but the latter was highly and negatively correlated with the frequency of greetings received ( $\mathrm{rs}=$ $3370.87, \mathrm{n}=19, \mathrm{p}=0.0001)$. In other words, the higher the wolves were in rank, the more greetings 338 they received. In particular, $60.99 \%$ of greetings were received by the breeding pair. At the 339 dyadic level, greeting was directed mainly from subordinates towards dominant individuals 340 (GLM: $\mathrm{z}=-7.51, \mathrm{p}<0.0001)$; it also occurred most often between partners with higher age 341 differences (GLM: $\mathrm{z}=5.91, \mathrm{p}<0.0001)$, with younger wolves displaying the behaviour more 342 often towards the older ones. The sex combination of the dyad did not affect the occurrence of 343 greeting $(\mathrm{GLM}: \mathrm{z}=0.37, \mathrm{p}=0.71)$. Overall, greeting was observed only in relatively few dyads.

344 Excluding the breeding pair, in such dyads, greeting was completely unidirectional with 345 subordinate wolves showing this behaviour towards dominant ones. 
The agonistic rank order was significantly but only mildly correlated with the age of the

348 wolves ( $r s=0.51, \mathrm{n}=19, \mathrm{p}=0.02$; Figure 2 ) while sex had no significant effect on dominance $\operatorname{rank}(\mathrm{U}=34, \mathrm{Z}=-0.90, \mathrm{p}=0.37)$. These results could mainly be due to some adult males who ranked at the bottom of the hierarchy. In particular, two of them (Storto and Procione, 17th and 18th rank position, respectively) showed lower levels of interactions (mean $\pm \mathrm{sd}$ of interaction:

$3.94 \pm 0.002$ ) and spent less time close to other wolves (mean $\pm \mathrm{sd}$ of the average dyadic association index, Clutton-Brock, 1982: $0.004 \pm 0.002)$ than all other pack members (mean $\pm \mathrm{sd}$ of interaction: $8.39 \pm 3.60$; mean \pm sd of the average dyadic association index: $0.03 \pm 0.01$ ).

Therefore, they appeared to be peripheral individuals in the pack who probably would have rank and age to be noticeably higher $(\mathrm{rs}=0.80, \mathrm{n}=17, \mathrm{p}=0.0001)$, while sex still has no effect $(\mathrm{U}=18, \mathrm{Z}=-1.73, \mathrm{p}=0.09)$. Overall, dominance relationships appeared to be influenced by age, with older wolves being dominant over younger individuals, but not by sex. submissive and aggressive behaviours were higher between female-female (FF) and male-male (MM) dyads than female-male dyads (submissive behaviours, GLM: FF-FM z $=-3.76, \mathrm{p}=$ 0.0004; MM-FM z = 4.04, $\mathrm{p}=0.0002$; aggressive behaviours, GLM: FF-FM z $=-5.19, \mathrm{p}=$ $0.001 ;$ MM-FM z $=3.25, p=0.003$ ) but no differences emerged between male-male and femalefemale dyads (submissive behaviours, GLM: FF-MM z $=-0.06, \mathrm{p}=0.99$; aggressive behaviours, GLM: FF-MM z = -1.59, $\mathrm{p}=0.24)$. Female-female dyads showed a frequency of dominance behaviours higher than female-male dyads (GLM: FF-FM z $=-5.20, \mathrm{p}=0.001)$ but no significant difference was found between all other combinations (GLM: MM-FM z =1.96, p =0.11; FF-

$\mathrm{MMz}=-2.13, \mathrm{p}=0.07)$ 
Based on these results we analysed the intra-sexual hierarchical organization. The

372 the proportion of transitive triangles relative to all triangles $(P t)$, and the triangle transitivity

373 metric $\left(t_{\text {tri }}\right)$ for each agonistic behavioural category in the two different contexts analysed (in the

374 presence of food and in its absence) are summarised in Table 5. Aggressive behaviour emerged as the best measure of dominance relationships between females since it showed the highest

376 value of linearity, complete triangle transitivity, and a rank order without any inconsistencies. A similar result was found for submissive behaviours between females, although it showed a low linearity due to the relatively high percentage of null dyads $(36.11 \%)$. However, the aggressive rank order was highly correlated to the submissive rank order $(r s=0.97, n=9, p=0.00002)$. The best measure of dominance relationships between males was based on submissive behaviours, no inconsistencies in the rank order. In fact, dominance behaviour between males also appeared to be a good measure of hierarchy and the relative rank order was highly correlated to that based on submissive behaviours ( $\mathrm{rs}=0.94, \mathrm{n}=10, \mathrm{p}=0.00006)$.

The female rank orders based on both aggressive and submissive behaviours and the male rank orders based on both submissive and dominance behaviours were highly correlated to the rank order that both sexes had in the entire inter-sexual hierarchy based on submissive behaviours (female aggressive behaviour: $\mathrm{rs}=0.98, \mathrm{n}=9, \mathrm{p}<0.00001$; female submissive behaviour: $\mathrm{rs}=0.98, \mathrm{n}=9, \mathrm{p}<0.00001$; male submissive behaviour: $\mathrm{rs}=0.93, \mathrm{n}=10, \mathrm{p}=$

0.0001; male dominance behaviour: $\mathrm{rs}=0.99, \mathrm{n}=10, \mathrm{p}<0.00001)$.

Female rank orders were positively correlated to age (aggressive rank order: $\mathrm{rs}=0.76, \mathrm{n}=$ 392 $9, \mathrm{p}=0.02$; submissive rank order: $\mathrm{rs}=0.83, \mathrm{n}=9, \mathrm{p}=0.005)$. For males, positive and 
393 significant correlations were found only when the two potentially dispersing adult males were

394 not considered (all males: submissive behaviour, $\mathrm{rs}=0.38, \mathrm{n}=10, \mathrm{p}=0.28$ and dominance

395 behaviour, $\mathrm{rs}=0.37, \mathrm{n}=10, \mathrm{p}=0.29$; without the two dispersing males: submissive behaviour,

$396 \mathrm{rs}=0.78, \mathrm{n}=10, \mathrm{p}=0.002$ and dominance behaviour, $\mathrm{rs}=0.79, \mathrm{n}=10, \mathrm{p}=0.002$ ).

397 Overall, although no sex effect emerged on the hierarchical rank order of the pack, both

398 males and females showed agonistic behaviours preferentially towards other males and females, 399 respectively. Sex-separate hierarchies showed higher linearity than the hierarchy including the

400 whole pack. Male hierarchical relationships appeared to be based on dominance and submissive

401 behaviours, while female hierarchal relationships appeared to be based on aggressive and

402 submissive behaviours.

403 Discussion

404 Using linearity (de Vries, 1995), triangle transitivity (Shizuka \& McDonald, 2014), matrix405 ranking procedures (MatMan; de Vries, 1998), and taking into account both the sex and ages of 406 the wolves in our pack, we found: 1) the existence of a clear linear hierarchy unaffected by the 407 competitive context and which remained solid also when the highest ranking individuals (the 408 breeding pair) were removed from analyses, 2) evidence suggesting the use of 'greeting' as a 409 formalised signal of subordination, and 3) partial support for the age-(and sex)-graded model. 410 1) Agonistic dominance relationships in the presence and absence of food

411 The main result of the current study is that the relationship between family pack members 412 of the Arctic wolves studied were not randomly distributed but rather, showed a high linear, 413 transitive, and significant hierarchy, which remained constant across both the feeding and non414 feeding contexts. Furthermore, we found that the best indicator of dominance, which resulted in 415 the clearest hierarchical relationship between individuals, was the direction of submissive 
416 behaviours (e.g. crouch, passive and active submission, flee, etc.). The breeding pair was

417 involved in most of the interactions, as previously reported also in other captive and wild packs

418 (e.g. Van Hooff \& Wensing, 1987, Mech, 1999), and although Shizuka \& McDonald (2015)

419 point out that linearity of a hierarchy may be 'skewed' due to dominant individuals showing

420 more behaviours than the rest, this was not the case in our study. Indeed results showed that a

421 linear and completely transitive hierarchy based on submissive behaviours was still highly

422 significant when the two top-ranking individuals were removed from the analyses. These results

423 indicate that clear dominance relationships exist among all siblings and confirm submissive

424 behaviours as a more reliable indicator of hierarchical relationships in the pack than aggressive

425 and dominance behaviours.

426 Although the common social structure in wild wolves is usually made up of the

427 reproducing parent pair and their offspring of the last two years, ranging from 2 to 15 individuals

428 (e.g. Bloch, 2002), families composed of several generations of up to 19-26 individuals (e.g.

429 Landau, 1993; White, 2001; VonHoldt, et al., 2008; Smith et al., 2011), have been described.

430 Hence our pack of Arctic wolves, composed of 5 generations and a total of 19 individuals, can be

431 considered representative of a multigenerational family pack of wolves. Therefore, the clear

432 presence of a linear hierarchy in our family pack of wolves goes against recent suggestions that

433 hierarchical relationships may only be adequate to describe atypical pack structures such as

434 disrupted families or forced packs of unrelated individuals (Mech \& Cluff, 2010) and rather

435 supports the importance of this concept also in describing the relationship between wolves in a

436 multi generational family pack.

437 A further confirmation of the importance of dominance relationships in wolves comes from

438 our second finding, that such relationships remained constant across competitive and non- 
439 competitive contexts. Indeed the dominance and submissive rank orders detected in the presence

440 of food were highly correlated to the respective rank orders detected in the absence of food. The

441 slight differences observed between the two contexts may be explained by the high percentage of

442 null dyads (Van Hoof \& Wensing, 1987). Indeed, when adding together all submissive and

443 dominant interactions occurring in the two contexts, we found improved values of linearity and

444 unidirectionality for both hierarchies, further indicating that dominance relationships in our

445 family pack were not influenced by the competitive context. In some mammal species, it may be

446 reasonable to predict the existence of asymmetries in fighting abilities and resource value,

447 especially between different age-sex classes, leading to different rank orders in different

448 contexts. Indeed, food is considered a major determinant of the reproductive success of

449 individuals hence, in species where females play the main role in rearing pups food should have

450 a higher value for them than for males, leading to a female over male dominance hierarchy

451 during feeding competition but not in other contexts. This has been found to be the case in both

452 chimpanzees and cats, where females raise their infants largely with no male intervention (e.g.

453 chimpanzees, Noë, de Waal, \& Van Hooff, 1980; domestic cats, Bonanni et al., 2007). However,

454 wolf packs rely on cooperation between all pack members in both rearing pups and providing

455 food; this may account for the consistency of dominance relationships and the absence of a

456 diverse effect of sex in the feeding and non-feeding context.

457 Submissive behaviours best fulfilled the criteria of agonistic dominance indicators since

458 they showed a higher linearity, a complete transitivity, and rank orders with no inconsistencies.

459 The importance of submissive behaviours in establishing and maintaining dominance

460 relationships have been widely highlighted in primates (Rowell, 1974; de Wall \& Luttrell, 1985)

461 but also in wolves (Schenkel, 1967; Mech, 1999). In our pack, subordinate individuals often 
462 determined the outcome of agonistic interactions by lowering themselves when being

463 approached by or when approaching dominant individuals, as described in wild wolf interactions

464 (Mech, 1999). Similar results have also been found in other captive family packs (Van Hooff \&

465 Wensing, 1987; Romero et al., 2014).

466 In sum, to date the results suggest that submissive behaviours play a more relevant role

467 than dominance displays in terms of maintaining dominance relationships between all members

468 of a family pack, although further investigation should assess the importance of submissive

469 behaviours in promoting friendly relations and pack cohesion in wolf pack, as has been

470 suggested by some authors (e.g. Mech, 1999).

471 2) Greeting as formal indicator of submission

472 Overall, our results showed that greeting in Arctic wolves partially fulfilled the criteria of a 473 formal signal of submission, although it occurred only in a limited number of dyads, it was

474 almost completely unidirectional and it was exhibited in line with the agonistic dominance

475 hierarchy, in that it was displayed mainly by subordinate individuals towards dominant ones. The

476 main exception was the breeding pair, in which this behaviour was exchanged equally. This is

477 particularly interesting considering that their relative position in the hierarchy was also not

478 always fixed; the male appearing dominant over the female when calculating the rank based on

479 dominance displays and vice versa when basing the rank on submissive behaviours. This might

480 indicate a relaxed dominance relationship between breeding partners, with the females prevailing

481 in some situations and the male in others, as described in other captive family packs (Van Hooff

$482 \&$ Wensing, 1987) and wild packs (e.g. Mech, 1999).

483 The frequency of greeting behaviours however, did not correlate with the agonistic rank

484 making it an unreliable measure on which to base the ordering of pack members in a consistent 
485 linear hierarchy. This was most likely due to the numerous dyads in which no greeting

486 behaviours were observed. Indeed greeting in wolves is widely described to occur upon reunion

487 after a period of separation and before travelling and hunting (e.g. Mech, 1999; Peterson et al., 488 2002). This context is limited in captivity, which may explain why, for many dyads, we were

489 unable to observe this behaviour. Nevertheless, with the only exception of the breeding pair, who

490 exchanged greetings exclusively towards each other, in all other dyads the behaviour was

491 completely unidirectional, displayed mainly from subordinates towards the dominant wolves and

492 with all pack members showing this behaviour most often towards the dominant breeding pair.

493 This is consistent with studies in other canids, showing that the use of greeting is a signal of

494 acknowledgment of dominance status (Ethiopian wolves, Sillero-Zubiri, et al 1996; domestic

495 dog, Cafazzo et al., 2010), and with theories suggesting that the mouth licking behaviour that

496 occurs during greeting interactions may be derived from food begging behaviour displayed from

497 the offspring towards the breeding pair to elicit regurgitation (Schenkel, 1967; Mech, Wolf \&

498 Packard, 1999).

\section{3) The age-(sex)-graded model}

500 In our pack we found an overall dominance hierarchy based on submissive behaviours in

501

502

503

504

505

506

507

which males were not, on average, higher in rank than females, but older wolves were dominant

over younger ones (with the exception of two adult males who ranked at the bottom of the

hierarchy). In wild wolf packs, it is usually reported that all members submit to the breeding pair, and the breeding female to the breeding male, with no clear dominance displays being observed between offspring (Mech, 1999; Bloch, 2002). In captive studies, males are mostly described as being dominant over females and older individuals over younger ones (e.g. Van Hooff \& Wensing, 1987; Romero et al., 2014). However, differently from the current study, previous 
508 work both in captivity and in the wild never statistically tested the effect of sex and age. Our 509 results support the effect of age, showing largely that older siblings are dominant over younger 510 ones, but do not support a sex effect of males being dominant over females.

511 Interestingly however, when looking at the frequency of the three main behavioural 512 categories used to calculate dominance relationships in our pack, we found that female-male 513 agonistic interactions were fewer compared to intra-sexual (female-female and male-male) 514 agonistic interactions. In other words, although an overall hierarchy including animals of both 515 sexes was detected, agonistic displays were not so frequently expressed in interactions between 516 females and males. In fact, females showed agonistic behaviours preferentially towards other

517 females and males towards other males. Taking into account this differential pattern of

518 behaviours, we calculated sex-separate linear hierarchies, which, in both cases, showed stronger 519 linearity than the mixed hierarchy. Moreover, dominance relationships appeared to be expressed 520 making use of different behavioural categories in male's and female's hierarchies. The best 521 hierarchies (in terms of unidirectionlity, linearity, and transitivity) in females were based on 522 aggressive and submissive interactions, whereas in males, hierarchies based on submission and 523 dominance behaviours showed better indices. Taken together, results suggest that although the 524 pack as a whole shows a clear hierarchical organization, the structure of the hierarchy within 525 each sex is even clearer. Furthermore, it appears that females and males may use different ways 526 to communicate their reciprocal rank when interacting with members of their own sex. Van

527 Hooff \& Wensing (1997) found similar results in a family pack of European wolves, where intra528 sexual relationships were characterized by a higher intensity of exchange of agonistic behaviour 529 than inter-sexual relationships. 
An unexpected result is that females, but not males, appeared to use aggression to

531

532

533

534

535

536

537

538

539

540

541

542

543

544

545

546

547

548

549

550

551

552

communicate their reciprocal status in interactions with other females. This result disagrees with

most of the studies on hierarchies outlining submission as the best measure of dominance

relationships (e.g. Rowel, 1974; Bernstein, 1981; Hand, 1986; Cafazzo et al., 2010). A potential

explanation is that in general, aggressive interactions were frequent between individuals of our

study pack, potentially due to the data being collected mostly during the breeding season, which

starts in January and lasts approximately until April. During this time the hierarchical structure of

the pack likely regulates breeding activity, and aggressive interactions may be used to more

forcefully maintain the status among individuals. Further studies are needed to ascertain whether

indeed the behaviours used to maintain the hierarchy are different during breeding and non-

breeding periods.

The greater linearity of the hierarchical organization and the differential patterns of

behaviours used to maintain it in males and females raises the question about the most

appropriate way to characterize the dominance relationships among members of a wolf pack. Are

sex-separate hierarchies a better model than all-member hierarchies to describe such

relationships? Several authors suggest that separate same-sex hierarchies best describe the social structure of wolf packs (Schenkel, 1947; Rabb, Woolpy \& Ginsburg, 1967; Zimen, 1975, 1978;

Derix et al. 1993; Derix \& VanHooff, 1995). Nevertheless, Zimen highlighted the existence of an overall hierarchy with males being dominant over females in each age class, which is also the usual model reported in studies of wild wolves (Clark, 1971; Mech, 1999). Unfortunately, as stated above, most of the previous studies carried out both in captivity and in the wild, did not follow a systematic procedure aimed to statistically show the dominance relationships in the pack, which makes a comparative assessment of results difficult. Based on current results, when 
553 considering the pack as a whole the hierarchical structure does not show males being dominant

554 over females, but given the stronger linearity indices of separate male and female hierarchies, it

555 would appear that status within sexes may carry an even greater weight than within the mixed

556 sex group.

557 A final point to consider is the validity of captive-based studies when attempting to

558 characterize the social structure of a wild species. It is undeniable that studies with wild animals

559 are preferable when exploring such topics, however it is perhaps interesting to note that in a

560 metanalyses involving 113 studies looking at dominance structures in 85 species (172 groups),

561 Shizuku and McDonald (2015) found that whether studies were conducted in the wild or in a

562 captive setting did not affect results. With such elusive species as wolves, partial reliance on

563 captive studies is probably unavoidable, however future research using the same methodologies

564 adopted here on wild animals would be particularly important to further our understanding of

565 wolves' social behaviour.

566 Conclusion

567 In conclusion, we emphasize the importance of applying a systematic methodology

568 including both age and sex in order to analyse dominance relationships between pack members.

569 Results clearly show that both within each sex and for the pack as a whole, dominance

570 relationships are a meaningful concept, which can be used to describe the structure of a multi-

571 generational family pack of captive wolves. Future studies analysing the potential effects of

572 dominance relationships on other aspects of the animal's lives will likely help to further establish

573 the importance of this concept to describe the social lives of wolves.

\section{Acknowledgement}


We are grateful to Dr. Jitka Vokurková, the director, and employees of Olomouc Zoo for

576 allowing us to run observations in their institution. Special thanks are due to Daizaburo Shizuka

577 for statistical advice and to Rachel Dale for language revision. We also thank two anonymous

578 referees for useful and constructive suggestions that improved the manuscript.

579

580 References

581 Altmann J. 1974. Observational study of behavior: sampling methods. Behaviour. 48:227-265.

582 Appleby MC. 1983. The probability of linearity in hierarchies. Anim Behav. 31:600-608.

583 Baan C, Bergmüller R, Smith DW \& Molnar B. 2014. Conflict management in free-ranging

$584 \quad$ wolves, Canis lupus. Animal Behaviour, 90, 327-334.

$585 \quad$ http://doi.org/10.1016/j.anbehav.2014.01.033

586 Bates D, Maechler M, Bolker B, Walker S. 2015. Fitting Linear Mixed-Effects Models Using

587 lme4. Journal of Statistical Software, 67(1), 1-48. doi:10.18637/jss.v067.i01.

588 Bernstein IS. 1981. Dominance: the baby and the bathwater. Behav Brain Sci. 4:419-457.

589 Bloch G. 2002. Alpha-concept, dominance \& leadership in wolf families. Wolf! Magazine Vol.

$590 \quad 20$, No.2

591 Bonanni R, Cafazzo S, Fantini C, Pontier D, Natoli E. 2007. Feeling order in an urban feral

592 domestic cat colony: relationship to dominance rank, sex and age. Anim Behav. 74:1369-

$593 \quad 1379$.

594 Cafazzo S, Valsecchi P, Bonanni R, Natoli E. 2010. Dominance in relation 586 to age, sex, and 595 competitive contexts in a group of free-ranging domestic dogs. Behav. Ecol. 21 (3), 443-

$596 \quad 455$. 
597 Clark KRF. 1971. Food habits and behavior of the tundra wolf on central Baffin island. Ph.D.

598 thesis, University of Toronto. Toronto, Ont. [Available from the National Library of

$599 \quad$ Canada, Ottawa, Ont.]

600 Derix R, Van Hooff J, Vries AD, Wensing J. 1993. Male and female mating competition in 601 wolves: female suppression vs. male intervention. Behaviour 127(1/2): 141-174.

602 Derix R. \& VanHooff J. 1995. Male and female partner preferences in a captive wolf pack: 603 specificity vs. spread of sexual attention. Behavior. 1-2: 132-149.

604 de Vries H, Netto WJ, Hanegraaf PLH. 1993. MatMan: a program for the analysis of sociometric 605 matrices and behavioural transition matrices. Behaviour 125:157-175 DOI

$606 \quad 10.1163 / 156853993 X 00218$.

607 .de Vries H. 1995. An improved test of linearity in dominance hierarchies containing unknown 608 or tied relationships. Anim Behav. 50:1375-1389.

609 de Vries H. 1998. Finding a dominance order most consistent with linear hierarchy: a new 610 procedure and review. Anim Behav. 55:827-843.

611 de Waal FBM \& Luttrell LM. 1985. The formal hierarchy of rhesus monkeys: An investigation of 612 the 615 bared teeth display. Am. J. Primatol., 9,73-85.

613 de Waal FBM. 1986. Deception in the natural communication of chimpazees. In RW Mitchell 614 \&NS Thompson (Eds), Decption: Perspectives on human and nonhuman deceit (pp. 221615 244). Albany: SUNY Press

616 de Waal FBM. 1989. Dominance 'style' and primate social organisation. In: Staden V, Foley 617 RA, editors. Comparative socioecology: the behavioural ecology of humans and other 618 mammals. Oxford: Blackwell Scientific. p. 243-263. 
619 Drews C. 1993. The concept and definition of dominance in animal behaviour. Behaviour.

620 125:283-313.

621 East ML \& Hofer H. 2001. Male spotted hyenas (Crocuta crocuta) queue for status in social 622 groups dominated by females. Behavioral Ecology, 12, 558-568.

623 Fatjo J, Feddersen-Petersen D, Ruiz de la Torre JL, Amat M, Mets M, Braus B, Manteca X. 2007. Ambivalent signals during agonistic interactions in a captive wolf pack. Appl. Anim. Behav. Sci 105, 274-283.

626

Feddersen-Petersen D. 2004. Hundepsychologie. Kosmos, Stuttgart, Germany, pp 113.

627

628

629

630

631

632

633

634

635

636

637

638

639

640

641

Fox MW. 1980. The soul of the wolf. Boston (MA): Little Brown.

Haber GC. 1977. Socio-ecological dynamics of wolves and prey in a subarctic ecosystem. Ph.D. thesis, University of British Columbia. Vancouver.

Hand JL. 1986. Resolution of social conflicts: dominance, egalitarianism, spheres of dominance, and game theory. Quart Rev Biol. 61(2):201-219.

Handcock M, Hunter D, Butts C, Goodreau S, Krivitsky P, Bender-deMoll S \& Morris M. 2015. statnet: Software Tools for the Statistical Analysis of Network Data_. The Statnet Project (<URL: http://www.statnet.org>). R package version 2015.11.0, <URL: CRAN.Rproject.org/package $=$ statnet $>$.

Klass K \& Cords M. 2011. Effect of unknown relationships on linearity, steepness and rank ordering of dominance hierarchies: simulation studies based on data from wild monkeys. BehaviouralProcesses 88:168-176 DOI 10.1016/j.beproc.2011.09.003.

Landau HG. 1951. On dominance relations and the structure of animal societies: I. Effect of inherent characteristics. Bulletin of Mathematical Biophysics 13:1-19 DOI $10.1007 / \mathrm{BF} 02478336$. 
642 Landau D. 1993. Wolf: spirit of the wild. The Nature Company, Berkeley, California, USA.

643 Mazzini F, Townsend SW, Virányi Z, Range F. 2013. Wolf howling is mediated by relationship

644 quality rather than underlying emotional stress. Current Biology, 23 (17): 1677-1680.

645 Mech LD. 1999. Alpha status, dominance, and division of labor in wolf packs. Can J Zool.

$646 \quad 77: 1196-1203$.

647 Mech LD. 2000. Leadership in wolf, Canis lupus, packs. Canadian Field Naturalist, 114, 259-

$648 \quad 263$.

649 Mech LD, Wolf PC, Packard JM. 1999. Regurgitative food transfer among wild wolves. Can J $650 \quad$ Zool 77: 1192-1195.

651 Mech LD \& Cluff HD. 2010. Prolonged intensive dominance behavior between grey wolves, 652 Canis lupus. Canadian Field-Naturalist 124, 215-218.

653 Modlmeier AP, Keiser CN, Watters JV, Sih A, Pruitt JN. 2014 The keystone individual concept: 654 an ecological and evolutionary overview. Animal Behaviour 89: 53-62. (DOI:

$655 \quad$ 10.1016/j.anbehav.2013. 12.020)

656 Noë R, De Waal FBM, Van Hooff JARAM. 1980. Types of dominance in a chimpanzee colony.

$657 \quad$ Folia Primatol. 34:90-110.

658 Norscia i \& Palagi E. 2015. The socio-matrix reloaded: from hierarchy to dominance profile in $659 \quad$ wild lemurs. PeerJ 3:e729; DOI 10.7717/peerj.729

660 Packard JM. 2003. Wolf behavior: reproductive, social and intelligent. In: Mech LD, Boitani L, 661 editors. Wolves: behavior, ecology, and conservation. Chicago and London: The 662 University of Chicago Press. p. 35-65. 
663 Peterson RO, Jacobs AK, Drummer TD, Mech LD, Smith DW. 2002. Leadership behaviour in 664 relation to dominance and reproductive status in gray wolves, Canis lupus. Can. J.Zool. 80, $665 \quad 1405-7181412$.

666 Preuschoft S. 1999. Are primates Behaviorists? Formal dominance, cognition and free floating 667 rationales. J. Comp . Psychol. 113, 91-95.

668 R Development Core Team. 2011. R: a language and environment for statistical computing. 669 Vienna: the R Foundation for Statistical Computing. Available at http://www.R$670 \quad$ project.org/.

671 Rabb GB, Woolpy JH, Ginsburg BE. 1967. Social relationships in a group of captive wolves. Am Zool. 7:305-312.

673

674

675

676

677

678

679

680

681

682

683

684

685

Romero T, Ito M, Saito A \& Hasegawa T. 2014. Social Modulation of Contagious Yawning in Wolves. PLoS ONE, 9(8), e105963. http://doi.org/10.1371/journal.pone.0105963

Rowell TE. 1974 The concept of social dominance. Behav. Biol. 11, 131-154. (doi:10.1016/S0091- 6773(74)90289-2).

Sands J \& Creel S. 2004. Social dominance, aggression and faecal glucocorticoid levels in a wild population of wolves, Canis lupus. Animal. Behaviour 67, 387-39.

Savage C. 1988. Wolves. San Francisco (CA): Sierra Club Books.

Schenkel R. 1947. Ausdruckstudien an Wölfen. Behaviour 1, 81-129.

Schenkel R. 1967. Submission: its features and function in the wolf and dg. Am Zool. 7:319329.

Shi A, Hanser SF, McHugh KA. 2009 Social network theory: new insights and issues for behavioral ecologists. Behavioral Ecology and Sociobiology 63: 975-988. (DOI: $10.1007 / \mathrm{s} 00265-009-0725-6)$ 
686 Shizuka D \& McDonald DB. 2012. A social network perspective on measurements of dominance 687 hierarchies. Animal Behaviour 83:925-934. (DOI 10.1016/j.anbehav.2012.01.011).

688 Shizuka D \& McDonald DB. 2014. Errata corrige to Shizuka D \&McDonald DB (Animal 689 Behaviour, 83, 925-934). Animal Behaviour 87: 243. (DOI

690 10.1016/j.anbehav.2013.10.016).

691

692

693

694

695

696

697

698

699

700

701

702

703

704

705

706

707 Journal of the Royal Society Interface 12: 105. (DOI: 10.1098/rsif.2015.0080)

Smith DW, Stahler DR, Stahler E, McIntyre R, Metz M, Irving J, Raymond R, Anton C, Kindermann R \& Bowersock N. 2012. Yellowstone Wolf Project: Annual Report, 2011. National Park Service, Yellowstone Center for Resources, Yellowstone National Park, Wyoming, YCR-2012-01.

StatSoft Italia srl 2005. STATISTICA (sistema software di analisi dei dati), versione 7.1. www.statsoft.it.

van der Borg JAM, Schilder MBH, Vinke CM, de Vries H. 2015. Dominance in Domestic Dogs: A Quantitative Analysis of Its Behavioural Measures. PLoS ONE 10(8): e0133978. doi:10.1371/journal. pone.0133978.

Van Hooff JARAM \& Wensing JAB. 1987. Dominance and its behavioural measures in a captive wolf pack. In: Frank HW, editor. Man and Wolf. Dordrecht, Olanda (Netherlands): Junk Publishers. p. 219-252.

Vervaecke, H., De Vries, H., Van Elsacker, L. 2000. Dominance and its behavioral measures in a captive group of bonobos (Pan paniscus). International Journal of Primatology, 21(1): 4768. 
708 VonHoldt BM, Stahler DR, Smith DW, Earl DA, Pollinger JP, Wayne RK. 2008. The genealogy

709 and genetic viability of reintroduced Yellowstone grey wolves. Molecular Ecology, 17, $710 \quad 252-274$.

711 Zimen E. 1975. Social dynamics of the wolf pack. In: Fox MW, editor. The wild Canids. New 712 York: Van Nostrand Reinhold. p. 336-362.

713 Zimen E. 1978. The wolf. Delacorte Press, New York.

714 Zimen E. 1982. A wolf pack sociogram. In: Harrington FH, Paquet PC, editors. Wolves of the 715 world: perspectives of behaviour, ecology and conservation. Park Ridge (NJ): Noyes

$716 \quad$ Publication. p. 282-322.

717 White AB. 2001. Wild and captive wolf (Canis lupus) aggression in relation to territory

718 availability and pack size. Honors thesis - University of Colorado, Boulder.

719 
720 Table 1. The group of arctic wolves (C. lupus arctos) housed at the Olomouc Zoo (Moravia, Czech Republic).

721 The animals were classified adult when older than 2 years and sub-adult when younger than 2 years.

$722 *$ This female was excluded from the analyses since she was removed after a short time from the beginning of the 723 study and her behavioural data were insufficient.

724

\begin{tabular}{|c|c|c|c|c|c|}
\hline Name & Sex & Date of birth & Age class & Removed & Returned \\
\hline Viki & Female & mar-04 & Adult & & \\
\hline Beta* & Female & apr-07 & Adult & 09-feb & \\
\hline Normale & Female & apr-12 & Sub-adult & 13-mar & \\
\hline Uno Beta & Female & apr-12 & Sub-adult & & \\
\hline Lacrima & Female & apr-12 & Sub-adult & & \\
\hline Volpe & Female & apr-12 & Sub-adult & 22-apr & 12-may \\
\hline Musocorto & Female & apr-12 & Sub-adult & & \\
\hline Husky & Female & apr-13 & Sub-adult & 13-mar & \\
\hline Sosia & Female & apr-13 & Sub-adult & & \\
\hline Cane & Female & apr-12 & Sub-adult & & \\
\hline Macchia & Male & mar-04 & Adult & & \\
\hline Maschera & Male & apr-09 & Adult & 13-mar & \\
\hline Sfregiato & Male & apr-09 & Adult & & \\
\hline Storto & Male & apr-09 & Adult & 13-mar & \\
\hline Procione & Male & apr-10 & Adult & 22-apr & \\
\hline Secondo & Male & may-11 & Adult & & \\
\hline Taglio & Male & apr-12 & Sub-adult & & \\
\hline Musolungo & Male & mag-11 & Adult & & \\
\hline Due & Male & apr-12 & Sub-adult & & \\
\hline Zampa & Male & apr-12 & Sub-adult & & \\
\hline
\end{tabular}

725

726 


\section{Table 2. Ethogram}

\begin{tabular}{|c|c|c|}
\hline $\begin{array}{l}\text { Behavioural } \\
\text { categories }\end{array}$ & $\begin{array}{l}\text { Behavioural } \\
\text { pattern }\end{array}$ & Description \\
\hline $\begin{array}{l}\text { Greeting } \\
\text { behaviours }\end{array}$ & Greeting & $\begin{array}{l}\text { To interact in a friendly and relaxed manner holding the ears back, showing much tail } \\
\text { wagging and licking of the other's mouth/muzzle. The subject however does not show } \\
\text { crouching/lowered hindquarters nor is the tail tucked between the legs }\end{array}$ \\
\hline \multicolumn{3}{|r|}{ 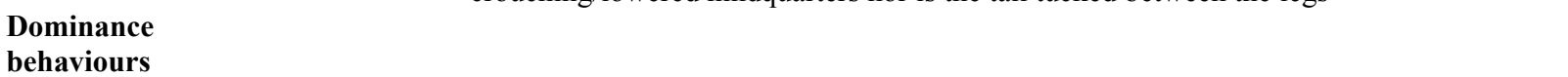 } \\
\hline & Stand tall & $\begin{array}{l}\text { Subject straightens up to full height, with a rigid posture and tail, may include raised } \\
\text { hackles, ears erect and tail perpendicular or above the back }\end{array}$ \\
\hline & Stand over & $\begin{array}{l}\text { To stand over another's body, with all four paws on the ground and the tail above the } \\
\text { plane of the back. The receiver may have either the whole body or just the forepaws } \\
\text { under the actors' belly/side }\end{array}$ \\
\hline & Paw on & To place one or both forepaws on the other's back \\
\hline & Ride up & To mount another one from behind or from the side, exhibiting a thrusting motion \\
\hline & Head on & $\begin{array}{l}\text { The subject approaches another's shoulder/back with the tail above the plane of the back } \\
\text { and puts its head on it. Most of times formation looks like a capital "T" }\end{array}$ \\
\hline & Muzzle bite & To grab the muzzle of another subject softly \\
\hline & $\begin{array}{l}\text { Approach } \\
\text { dominant }\end{array}$ & $\begin{array}{l}\text { To approach another subject within one body length for at least } 5 \text { seconds, with the tail } \\
\text { perpendicular or above the plane of the back and the ears erect and pointed forward }\end{array}$ \\
\hline \multicolumn{3}{|r|}{ 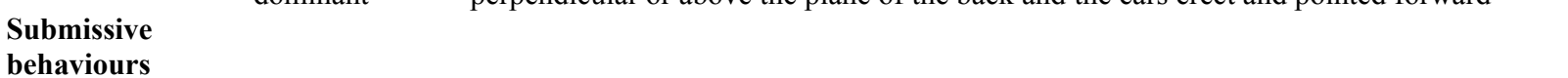 } \\
\hline & Crouch & $\begin{array}{l}\text { Lowering the head, sometimes bending the legs, arching the back, lowering the tail } \\
\text { between the hind legs, and avoiding eye contact }\end{array}$ \\
\hline & $\begin{array}{l}\text { Passive } \\
\text { submission }\end{array}$ & $\begin{array}{l}\text { To lie on the back showing the stomach and holding the tail between the legs. The ears } \\
\text { are held back and close to the head and the subject raises a hind leg for inguinal } \\
\text { presentation }\end{array}$ \\
\hline & $\begin{array}{l}\text { Active } \\
\text { submission }\end{array}$ & $\begin{array}{l}\text { The subject has its tail tucked between the hind legs sometimes wagging it while he is in } \\
\text { a crouched position (with hindquarters lowered) and may attempt to paw and lick the side } \\
\text { of actors'/aggressor's muzzle. The behaviour may include urination. }\end{array}$ \\
\hline & Withdrawing & $\begin{array}{l}\text { The subject withdraws from another moving away slowly in the opposite direction, } \\
\text { displaying a submissive posture. It occurs when a subject has been threatened or attacked } \\
\text { by another, or a fight has taken place }\end{array}$ \\
\hline & Flee & $\begin{array}{l}\text { To run away from another with tail tucked between the legs and body ducked. It occurs } \\
\text { when a subject has been threatened or attacked by another, or after a fight }\end{array}$ \\
\hline & Avoidance & $\begin{array}{l}\text { In response to another reducing the distance towards it, the subject moves away } \\
\text { displaying a submissive posture. The subject may also look at the individual he is trying } \\
\text { to avoid }\end{array}$ \\
\hline & $\begin{array}{l}\text { Approach } \\
\text { submissive }\end{array}$ & $\begin{array}{l}\text { To slowly approach another within one body length remaining within that distance for at } \\
\text { least } 5 \text { seconds. The approach is characterized by a ducked posture and tail between the } \\
\text { legs. Subject can also be moving in a wavy line and in a hesitant (stop-start) manner }\end{array}$ \\
\hline \multicolumn{3}{|r|}{ 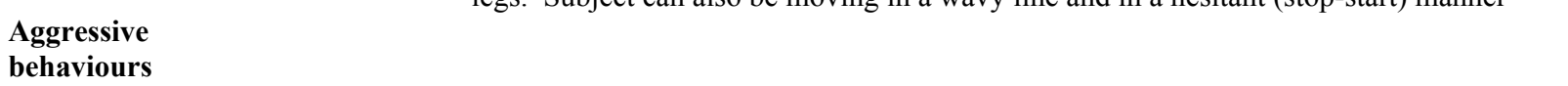 } \\
\hline & Threat & $\begin{array}{l}\text { Subject orients towards another performing one or more of the following: staring intently } \\
\text { at, curling of the lips, baring of the canines, raising the hackles, snarling, growling, and } \\
\text { barking, sometimes with the tail perpendicular or above the back }\end{array}$ \\
\hline & Attack & $\begin{array}{l}\text { Running into or jumping onto another with tail, ears and sometimes hackles up, often } \\
\text { with bites at the neck }\end{array}$ \\
\hline & Knock down & $\begin{array}{l}\text { To strike another subject sharply with the chest or shoulder so that the other falls to the } \\
\text { ground }\end{array}$ \\
\hline & Pin & $\begin{array}{l}\text { To grab another at the neck or at the muzzle, forcing it down to the ground and holding it } \\
\text { there }\end{array}$ \\
\hline & Chase & A subject runs after a conspecific, exhibiting threatening behaviours (see 'threat' above) \\
\hline & Snapping & To snap teeth into the air, noisily \\
\hline & Bite & Bite a conspecific, without inhibition, with enough pressure to cause potential injury \\
\hline
\end{tabular}


729 Table 3. Summary of values of the directionality (directional consistency index, DCI), linearity h' and its

730 significance level, number and strength of inconsistencies (No. I and SI, respectively) for the I\&SI rank orders, and

731 triangle transitivity (proportion of transitive triangles relative to all triangles $\mathrm{P}_{\mathrm{t}}$, triangle transitivity metric $\mathrm{t}_{\text {tri }}$, and

732 significance level) for all behavioural categories in the absence, and in the presence, of food and for all dominance

733 and submissive interactions regardless of the context.

\begin{tabular}{|c|c|c|c|c|}
\hline \multicolumn{5}{|c|}{ Agonistic behaviours displayed in the absence of food } \\
\hline & Directionality & Linearity & $\begin{array}{l}\text { Inconsistency: } \\
\text { No. I (and SI) }\end{array}$ & Triangle transitivity \\
\hline Aggressive behaviour & $\mathrm{DCI}=0.94$ & No $\left(h^{\prime}=0.25, p=0.08\right)$ & - & $\mathrm{P}_{\mathrm{t}}=0.88, \mathrm{t}_{\mathrm{tri}}=0.52, \mathrm{p}=0.009$ \\
\hline Dominance behaviour & $\mathrm{DCI}=0.97$ & Yes $\left(h^{\prime}=0.38, \mathrm{p}=0.002\right)$ & $1(3)$ & $\mathrm{P}_{\mathrm{t}}=0.99, \mathrm{t}_{\mathrm{tri}}=0.97, \mathrm{p}=0.000$ \\
\hline Submissive behaviour & $\mathrm{DCI}=0.98$ & Yes $\left(\mathrm{h}^{\prime}=0.45, \mathrm{p}=0.0001\right)$ & $1(2)$ & $\mathrm{P}_{\mathrm{t}}=0.99, \mathrm{t}_{\mathrm{tri}}=0.97, \mathrm{p}=0.000$ \\
\hline \multicolumn{5}{|c|}{ Agonistic behaviours displayed in the presence of food } \\
\hline & Directionality & Linearity & $\begin{array}{l}\text { Inconsistency: } \\
\text { No. I (and SI) }\end{array}$ & Triangle transitivity \\
\hline Aggressive behaviour & $\mathrm{DCI}=0.85$ & Yes $\left(h^{\prime}=0.36, p=0.003\right)$ & $4(24)$ & $\mathrm{P}_{\mathrm{t}}=0.98, \mathrm{t}_{\mathrm{tri}}=0.90, \mathrm{p}=0.000$ \\
\hline Dominance behaviour & DCI $=0.99$ & Yes $\left(h^{\prime}=0.33, p=0.006\right)$ & $1(4)$ & $\mathrm{P}_{\mathrm{t}}=1.00, \mathrm{t}_{\mathrm{tri}}=1.000, \mathrm{p}=0.000$ \\
\hline Submissive behaviour & $\mathrm{DCI}=0.99$ & Yes $\left(h^{\prime}=0.30, p=0.02\right)$ & $1(2)$ & $\mathrm{P}_{\mathrm{t}}=0.99, \mathrm{t}_{\mathrm{tri}}=0.95, \mathrm{p}=0.000$ \\
\hline \multicolumn{5}{|c|}{ Agonistic behaviours displayed in both the absence and the presence of food } \\
\hline & Directionality & Linearity & $\begin{array}{l}\text { Inconsistency: } \\
\text { No. I (and SI) }\end{array}$ & Triangle transitivity \\
\hline All dominance behaviours & DCI $=0.97$ & Yes $\left(h^{\prime}=0.58, p=0.0001\right)$ & $2(9)$ & $\mathrm{P}_{\mathrm{t}}=0.992, \mathrm{t}_{\mathrm{tri}}=0.970, \mathrm{p}=0.000$ \\
\hline All submissive behaviours & $\mathrm{DCI}=0.97$ & Yes $\left(\mathrm{h}^{\prime}=0.56, \mathrm{p}=0.0001\right)$ & 0 & $\mathrm{P}_{\mathrm{t}}=1.000, \mathrm{t}_{\mathrm{tri}}=1.000, \mathrm{p}=0.000$ \\
\hline \multicolumn{5}{|c|}{ Agonistic behaviours displayed in both the absence and the presence of food without considering the alpha male and femal } \\
\hline & Directionality & Linearity & $\begin{array}{l}\text { Inconsistency: } \\
\text { No. I (and SI) }\end{array}$ & Triangle transitivity \\
\hline All dominance behaviours & $\mathrm{DCI}=0.96$ & Yes $\left(h^{\prime}=0.44, p=0.0008\right)$ & $2(9)$ & $\mathrm{P}_{\mathrm{t}}=0.983, \mathrm{t}_{\mathrm{tri}}=0.932, \mathrm{p}=0.000$ \\
\hline All submissive behaviours & $\mathrm{DCI}=0.94$ & Yes $\left(h^{\prime}=0.40, p=0.005\right)$ & 0 & $\mathrm{P}_{\mathrm{t}}=1.000, \mathrm{t}_{\mathrm{tri}}=1.000, \mathrm{p}=0.000$ \\
\hline
\end{tabular}


736 Table 4. Dominance relationships based on all submissive behavioural patterns recorded between wolves.

737 Bold type: males; italic type: females. The signallers, who are the performers of the submissive behaviours, are

738 listed in rows, whereas the recipients in columns.

\begin{tabular}{|c|c|c|c|c|c|c|c|c|c|c|c|c|c|c|c|c|c|c|c|}
\hline & vik & mac & mas & sec & sfr & zam & due & $u n b$ & vol & lac & nor & can & tag & mul & тис & sos & sto & pro & hus \\
\hline vik & $*$ & 0 & 0 & 0 & 0 & 0 & 0 & 0 & 0 & 0 & 0 & 0 & 0 & 0 & 0 & 0 & 0 & 0 & 0 \\
\hline mac & 1 & $*$ & 0 & 0 & 0 & 0 & 0 & 0 & 0 & 0 & 0 & 0 & 0 & 0 & 0 & 0 & 0 & 0 & 0 \\
\hline mas & 1 & 14 & $*$ & 0 & 0 & 0 & 0 & 0 & 0 & 0 & 0 & 0 & 0 & 0 & 0 & 0 & 0 & 0 & 0 \\
\hline sec & 3 & 14 & 4 & $*$ & 2 & 0 & 0 & 0 & 0 & 0 & 0 & 0 & 0 & 0 & 0 & 0 & 0 & 0 & 0 \\
\hline sfr & 2 & 4 & 13 & 4 & $*$ & 0 & 0 & 0 & 0 & 0 & 0 & 0 & 0 & 0 & 0 & 0 & 0 & 0 & 0 \\
\hline zam & 0 & 3 & 0 & 0 & 0 & $*$ & 0 & 0 & 0 & 0 & 0 & 0 & 0 & 0 & 0 & 0 & 0 & 0 & 0 \\
\hline due & 1 & 10 & 3 & 2 & 1 & 0 & $*$ & 0 & 0 & 0 & 0 & 0 & 0 & 0 & 0 & 0 & 0 & 0 & 0 \\
\hline$u n b$ & 48 & 6 & 1 & 0 & 0 & 0 & 1 & $*$ & 0 & 0 & 0 & 0 & 0 & 0 & 0 & 0 & 0 & 0 & 0 \\
\hline vol & 31 & 4 & 1 & 2 & 2 & 0 & 0 & 2 & $*$ & 0 & 0 & 0 & 0 & 1 & 0 & 0 & 0 & 0 & 0 \\
\hline lac & 27 & 3 & 1 & 2 & 1 & 0 & 0 & 1 & 9 & $*$ & 0 & 0 & 0 & 1 & 0 & 0 & 0 & 0 & 0 \\
\hline nor & 3 & 1 & 0 & 0 & 0 & 0 & 0 & 0 & 4 & 6 & $*$ & 0 & 0 & 0 & 0 & 0 & 0 & 0 & 0 \\
\hline can & 1 & 2 & 0 & 0 & 0 & 0 & 0 & 3 & 0 & 6 & 0 & $*$ & 0 & 0 & 0 & 1 & 0 & 0 & 0 \\
\hline tag & 2 & 13 & 3 & 0 & 7 & 1 & 1 & 0 & 0 & 0 & 0 & 0 & $*$ & 0 & 0 & 0 & 1 & 0 & 0 \\
\hline mul & 5 & 22 & 10 & 0 & 10 & 0 & 0 & 1 & 1 & 2 & 0 & 0 & 0 & $*$ & 0 & 0 & 0 & 0 & 0 \\
\hline muc & 11 & 13 & 0 & 2 & 2 & 0 & 1 & 1 & 8 & 16 & 1 & 42 & 1 & 1 & $*$ & 2 & 0 & 0 & 0 \\
\hline SOS & 1 & 2 & 0 & 0 & 1 & 1 & 1 & 0 & 0 & 0 & 0 & 1 & 0 & 0 & 11 & $*$ & 0 & 0 & 0 \\
\hline sto & 4 & 4 & 3 & 0 & 1 & 0 & 0 & 1 & 2 & 1 & 2 & 0 & 4 & 0 & 2 & 0 & $*$ & 0 & 0 \\
\hline pro & 1 & 23 & 3 & 2 & 5 & 2 & 7 & 1 & 0 & 1 & 0 & 7 & 2 & 5 & 3 & 1 & 1 & $*$ & 0 \\
\hline hus & 2 & 1 & 4 & 0 & 0 & 1 & 0 & 0 & 0 & 1 & 0 & 0 & 0 & 1 & 0 & 0 & 0 & 1 & $*$ \\
\hline
\end{tabular}


741 Table 5. Summary of values of the directionality (directional consistency index, DCI), linearity h' and its

742 significance level, number and strength of inconsistencies (No. I and SI, respectively) for the I\&SI rank orders, and

743 triangle transitivity (proportion of transitive triangles relative to all trangles $\mathrm{P}_{\mathrm{t}}$, triangle transitivity metric $\mathrm{t}_{\text {tri }}$, and

744 significance level) for all behavioural categories for females and males separately.

\begin{tabular}{|c|c|c|c|c|}
\hline & Directionality & Linearity & $\begin{array}{l}\text { Inconsistency: } \\
\text { No. I (and SI) }\end{array}$ & Triangle transitivity \\
\hline Female aggressive behaviour & $\mathrm{DCI}=0.92$ & Yes $\left(h^{\prime}=0.78, p=0.004\right)$ & 0 & $\mathrm{P}_{\mathrm{t}}=1.000, \mathrm{t}_{\mathrm{tri}}=1.000, \mathrm{p}=0.008$ \\
\hline Female dominance behaviour & $\mathrm{DCI}=0.98$ & Yes $\left(h^{\prime}=0.74, p=0.007\right)$ & $1(2)$ & $\mathrm{P}_{\mathrm{t}}=0.973, \mathrm{t}_{\mathrm{tri}}=0.892, \mathrm{p}=0.004$ \\
\hline Female submissive behaviour & $\mathrm{DCI}=0.98$ & Yes $\left(h^{\prime}=0.59, p=0.048\right)$ & 0 & $\mathrm{P}_{\mathrm{t}}=1.000, \mathrm{t}_{\mathrm{tri}}=1.000, \mathrm{p}=0.008$ \\
\hline \multicolumn{5}{|c|}{ Agonistic behaviours displayed between males } \\
\hline & Directionality & Linearity & $\begin{array}{l}\text { Inconsistency: } \\
\text { No. I (and SI) }\end{array}$ & Triangle transitivity \\
\hline Male aggressive behaviour & $\mathrm{DCI}=0.90$ & Yes $\left(h^{\prime}=0.61, p=0.015\right)$ & $1(4)$ & $\mathrm{P}_{\mathrm{t}}=0.972, \mathrm{t}_{\mathrm{tri}}=0.889, \mathrm{p}=0.002$ \\
\hline Male dominance behaviour & $\mathrm{DCI}=0.96$ & Yes $\left(h^{\prime}=0.78, p=0.0009\right)$ & 0 & $\mathrm{P}_{\mathrm{t}}=1.000, \mathrm{t}_{\mathrm{tri}}=1.000, \mathrm{p}=0.001$ \\
\hline Male submissive behaviour & $\mathrm{DCI}=0.97$ & Yes $\left(h^{\prime}=0.81, p=0.0002\right)$ & 0 & $\mathrm{P}_{\mathrm{t}}=1.000, \mathrm{t}_{\mathrm{tri}}=1.000, \mathrm{p}=0.001$ \\
\hline
\end{tabular}

745 


\section{Figure 1.}

748 The relation between the rank order based on all dominance behaviours and the rank order based

749 on all submissive behaviours.

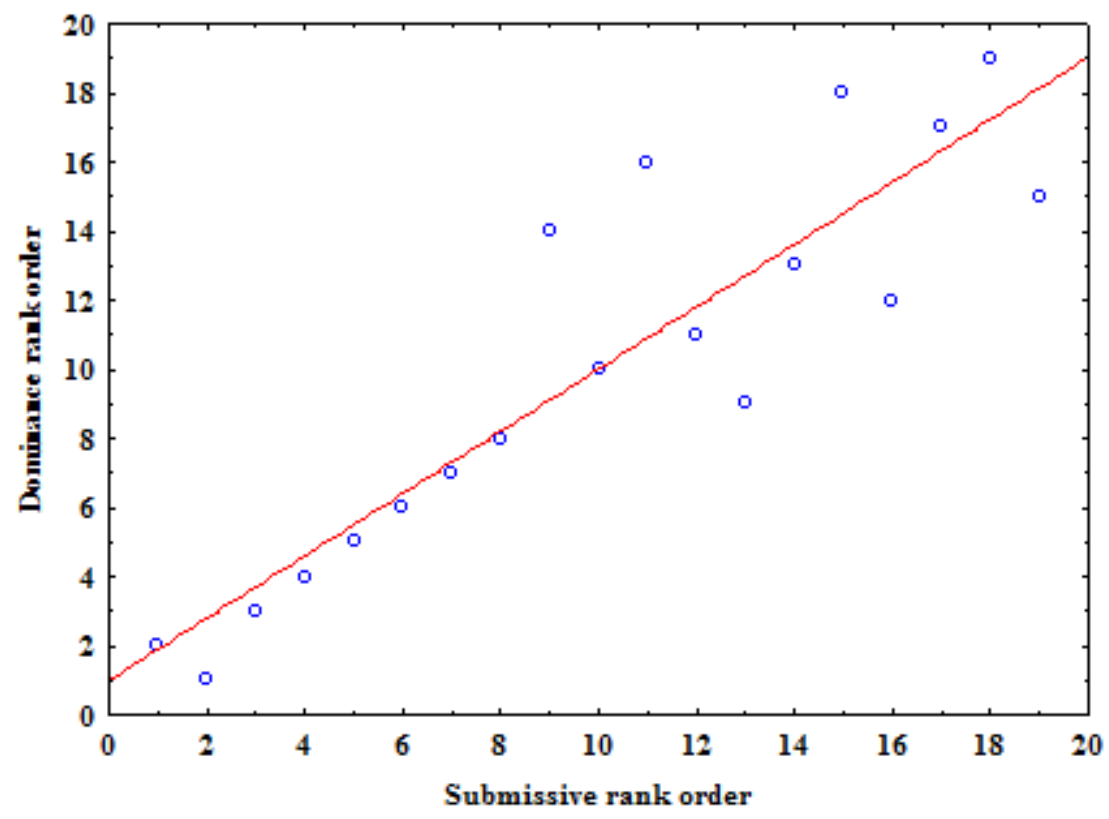

750

751

752 


\section{Figure 2.}

754 The relation between the agonistic rank order based on submission and the age of wolves.

755

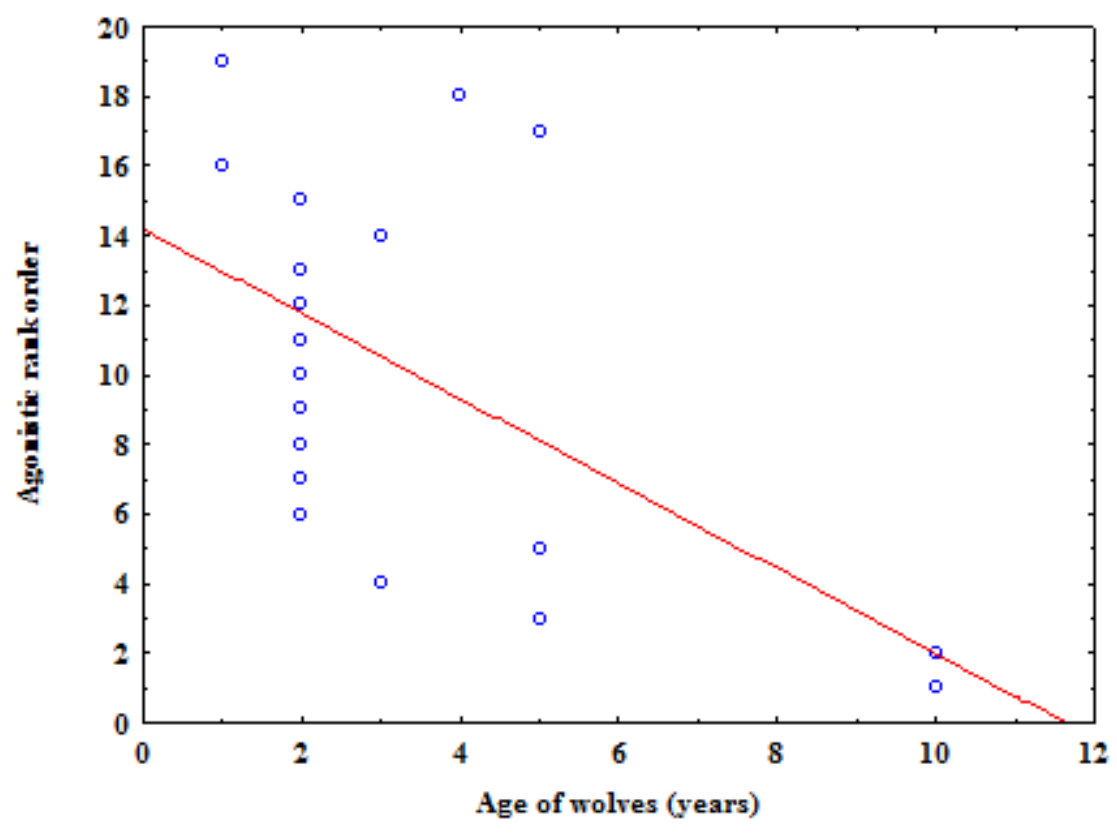

